\title{
Neural integrative activities of nucleus accumbens subregions in relation to learning and motivation
}

\author{
ANN E. KELLEY \\ University of Wisconsin-Madison Medical School, Madison, Wisconsin
}

\begin{abstract}
In recent years, there has been much interest in the functional specializations of nucleus accumbens subregions. The two zones within the nucleus accumbens that have received considerable attention are the accumbens core, consisting of ventral striatal tissue surrounding the anterior commissure, and the accumbens shell, which envelops the core on its medial, ventral, and lateral borders. Differential connectivity and histochemical profiles suggest that these two subterritories may have distinctive behavioral roles with regard to the regulation of motivated behavior. Experiments focusing primarily on amino acid-coded neurotransmitter systems in these regions-that is, glutamate and gamma-amino butyric acid (GABA) - have revealed specific and contrasting functions of the core and the shell. It is proposed that the accumbens core, and specifically $N$-methyl-D-aspartate receptor-dependent plasticity within this area, is part of a network critical for appetitive instrumental learning, in which a motor response becomes "stamped in" when followed by a rewarding stimulus or event. The accumbens shell, particularly GABA and alpha-amino-3-hydroxy-5-methylisoxazole-4-propionic acid receptors within the shell, is implicated in the executive control of brain feeding circuits and may also represent a key area at which appetitive and aversive stimuli interact to control behavioral selection. These functional specializations within the nucleus accumbens subregions may be integrated through the coordination of activity within striatal neuronal ensembles that communicate with complex networks of limbic, thalamic, and prefrontal circuitry.
\end{abstract}

In 1980, the Canadian physiological psychologist Gordon Mogensen wrote a landmark paper entitled "From Motivation to Action: Functional Interface Between the Limbic System and the Motor System" (Mogenson, Jones, \& Yim, 1980). In this review, Mogenson proposed that a basal forebrain structure called the nucleus accumbens was a critical interface between two major functional realms within the brain: the so-called limbic system, which was responsible for the elaboration of motivational states and emotions, and the motor system, which mediated the production of behavioral actions. It was well established at that point (mostly from lesion and stimulation studies) that limbic forebrain structures - such as the amygdala, the hypothalamus, and related structures - were important for the neural integration of basic drives and goal-directed behaviors essential for biological survival, including feeding, drinking, sexual and reproductive behaviors, aggression, and exploration (MacLean, 1949; Stellar, 1954; Valenstein, 1969). There was also evidence accruing at this time for complex cognitive functions of the association cortex. Classic neuropsychological studies showed that areas such as the prefrontal cortex and the temporal lobe were involved in learning, memory, planning, and emotional functions (Kluver \& Bucy, 1939; Mountcastle, Lynch,

This work was supported by grants DA04788 and DA09311 from the National Institute on Drug Abuse. Correspondence concerning this article should be addressed to A. E. Kelley, Department of Psychiatry, University of Wisconsin-Madison Medical School, 6001 Research Park Blvd., Madison, WI 53719 (e-mail: aekelley@macc.wisc.edu).
Georgopoulos, Sakata, \& Acuna, 1975; Nauta, 1971; Pribam, 1969). In addition, work begun in the 1970s suggested that brain dopamine pathways, arising from the midbrain to innervate forebrain limbic structures, also played a key role in the modulation of these goal-directed behaviors. Mogenson noted that many of these brain regions involved in emotion or cognition had connections to the nucleus accumbens. He also observed that recent anatomical studies showed that the nucleus accumbens appeared to be anatomically interposed between the limbic system and the motor system, perhaps acting to translate thoughts and emotions into movements. The requirement for this integrative function had been noted earlier by Kornhuber (1974). He commented that "movements are parts of actions, and actions have to satisfy the needs of organisms and secure the survival of the species" (p. 267). Mogenson also commented that, although neurophysiologists had spent much time studying posture, movement, and sensory functions, the neural mechanisms that initiate biologically significant actions contributing to adaptation and survival had been a relatively neglected subject. Certainly, this situation has been rectified in recent years. A literature search for the years 1980,1990 , and 1997 reveals 73,305 , and 409 published papers, respectively, pertaining to the nucleus accumbens. The thesis of the present review will be that there are two central features of the neural integrative activities of the nucleus accumbens, which are subserved by the two recently defined subterritories of the nucleus accumbens-the core and the shell (Alheid \& Heimer, 1988; Zahm \& Brog, 1992). These two functions, 
which will be elaborated in detail below, constitute the learning of adaptive motor responses and the control of brain feeding circuits.

\section{Historical Framework for Theories Pertaining to the Nucleus Accumbens}

Both of these proposed functions have their conceptual roots in a number of theories that attempted to explain motivated behavior and learning. Perhaps the most important of these for the present hypotheses is Thorndike's law of effect, which stated that behavioral acts followed by "satisfaction" to the organism would tend to be repeated in the future, whereas behavioral acts followed by negative consequences would diminish in their occurrence (Thorndike, 1911). In other words, the law of effect states that learning consists of the reinforcing of a connection between a response and a stimulus situation, and this strengthening is dependent on the response being followed by a positive event that is, presumably, beneficial to the animal in some way. This notion was the basis of connectionism, which dominated American psychology for nearly half a century. In fact, many years earlier, the Darwinian Herbert Spencer (1872) anticipated the law of effect when he wrote that animals persist in acts that result in pleasure and refrain from actions resulting in pain. Indeed, Spencer saw that pain and pleasure were important principles in evolution and adaptive behavior. The philosophical notion of hedonism (the experience of pleasantness or unpleasantness) has its roots in many earlier writings, starting with the ancient Greeks and influencing the British associationists, such as Thomas Hobbes and John Stuart Mill.

Clark Hull formulated a system to explain learning that was largely based in the stimulus-response (S-R) tradition but that integrated many developments by other theorists (Hull, 1943). Hull's original focus was strongly Pavlovian, but he soon extended the principles of Pavlovian conditioning to understanding complex instrumental behaviors. One of his most important contributions to learning theory, and one that is closely related to many current ideas about the nucleus accumbens more than 50 years later, is his integration of the concept of drive, or biological need, with reinforcement and the strengthening of behavior. Hull was one of the first formal learning theorists to adopt a strongly biological point of view, and he felt that the ultimate function of behavior in an animal was to solve its biological problems. He proposed that the deprivation state, such as food or water deprivation, energized behavior nonspecifically. This activation increased the probability that an adaptive response would occur. Let us imagine, for example, a very hungry, exploratory rat accidentally bumping into a lever that provides a food pellet (reinforcement). The reduction of drive (and, in Hull's later writings, drive-stimulus reduction, or reduction of cravings) that results with the reinforcement causes the animal to repeat the response and to engage in learning. In Hull's scheme, he called the S-R connection habit and postulated that drive and habit multiply together to determine the strength of behavior. Bolles (1975) nicely summarizes this state of affairs: "What an elegant system we would have if this event, the reduction of need, were to serve as reinforcement and produce learning of the lucky response! The animal would then be, in effect, an automatic problem-solving system" (p. 95). The concept of habit is important, because it has contributed substantially to current thinking about the basal ganglia and learning. Moreover, Hull implied in his postulates that the strengthening of habit was dependent on specific neural events that are triggered by the temporal contiguity of the rewarding stimulus and the action: "Habit strength increases when receptor and effector activities occur in close temporal contiguity, provided their approximately contiguous occurrence is associated with primary or secondary reinforcement" (p. 178). As will be expounded below, this notion may provide a conceptual basis for the neuromolecular events within the accumbens that are associated with response learning. Of course, it is important to emphasize that Hull's system was not able to adequately describe all forms of learning, and in the decades that ensued, many other theories concerning motivation, learning, and memory and their neural concomitants gained prominence (e.g., Bindra, 1968, 1978; Dickinson, 1980; Solomon \& Corbit, 1974; Spence, 1947). Nevertheless, Hull had an enormous impact on conceptual developments in physiological psychology.

A discussion of influential historical developments concerning learning is not complete without mention of Hebb, who first postulated synaptic modification as the basis for learning. Actually, it was William James who first made a connection between "cerebral physiology" and the laws of association (as cited in T. H Brown, Kairiss, \& Keenan, 1990): "How does man come, after having the thought of $A$, to have the thought of $B$ the next moment? or how does he come to think of thought $A$ and B always together?" (James, 1890, p. 225). James proposed that "there is no other elementary causal law of association than the law of neural habit: When two elementary brain processes have been active together or in immediate succession, one of them, on recurring, tends to propagate its excitement into the other" (p. 226). Hebb expanded this notion and formulated what became known as Hebb's postulate of learning: "When an axon of cell A is near enough to excite cell B or repeatedly or consistently takes part in firing it, some growth process or metabolic change takes place in one or both cells such that A's efficiency, as one of the cells firing B, is increased" (Hebb, 1949, p. 62). This formulation has served as the conceptual basis for investigation of the neural and molecular basis of memory over the past 50 years. Although the great majority of this research has focused on structures such as the hippocampus, the amygdala, and the cortex, in recent years several models of neuronal plasticity in relation to learning have been proposed for basal ganglia structures as well (Houk, Adams, \& Barto, 1995; Mulder, Arts, \& Lopes da Silva, 1997; Wickens \& Kötter, 1995; Wise, Murray, \& Gerfen, 1996). 
Another set of historical developments that pertains to the current hypotheses concerning the nucleus accumbens grew out of classical studies on the physiology of motivation. In the tradition of the great physiologists Claude Bernard and Walter Cannon, who described the fundamental principles of homeostasis, early students of motivation began to investigate behaviors such as eating and drinking from a neurophysiological perspective. One of the most influential of these investigators was Curt Richter, who conceived of the idea that motivated behaviors served to maintain the internal homeostatic environment, in coordination with more automatic mechanisms. Thus, motivated behaviors-such as feeding, drinking, nest-building, or temperature-regulating behaviors-were self-regulatory and highly sensitive to fluctuating internal conditions of the organism. Karl Lashley (1938) also made an important contribution along these lines, with his paper, "An Experimental Analysis of Instinctive Behavior." In this work, he posed critical questions-for example, where in the brain is there an excitatory process, like Sherrington's central excitatory state, that can be the basis of such biological drives as sex, maternal behavior, emotion, hunger, and thirst? A further significant contribution was the work of Eliot Stellar, who was among the first to develop a truly integrative theory of motivation on the basis of brain-behavior relationships. He drew attention to the hypothalamus and postulated that "the major focus of the neural system or the integrating mechanism responsible for the arousal, execution and satiation of motivated behavior lies in the diencephalon, probably the hypothalamus" (Stellar, 1960, p. 1506). In his classic papers, he synthesized significant theoretical constructs, such as drive, goal-directed behavior, instinct, sensation, and learning, with the current empirical data, forming a broad conceptual framework (Stellar, 1954, 1960). Although his major focus was on the hypothalamus, Stellar also suggested that "central neural structures outside of the hypothalamus also contribute excitatory and inhibitory influences to the control of motivation" (p. 1524). Indeed, recent work on the nucleus accumbens, as will be described below, demonstrates its key role in this regard, with there being significant functional connections to the hypothalamus.

\section{Reconceptualization of the Nucleus Accumbens: Core and Shell Subterritories}

The anatomical organization of the nucleus accumbens is well suited to its hypothetical role as a limbicmotor integrator. Within this area, there is a convergence of afferents conveying information, related to affective and motivational states, arising from limbic structures such as the amygdala, the hippocampus, the prefrontal cortex, midbrain monoamine systems, and brainstem autonomic centers (Beckstead, 1979; Brog, Salyapongse, Deutch, \& Zahm, 1993; Kelley \& Domesick, 1982; Kelley, Domesick, \& Nauta, 1982; A. J. McDonald, 1991). Furthermore, it has extensive connections to skeletal motor and visceral motor output systems (Groenewegen
\& Russchen, 1984; Heimer, Zahm, Churchill, Kalivas, \& Wohltmann, 1991; Nauta, Smith, Faull, \& Domesick, 1978). Although the nucleus accumbens has long been considered a ventral striatal territory with prominent similarities to the overlying caudate-putamen, in recent years there has been a major anatomical reconceptualization of this structure on the basis of a refined anatomical analysis. The analysis of connectivity, as well as its histochemical profile, indicates that the nucleus accumbens is composed of three major subterritories, which have been termed the core, the shell, and the rostral pole. The core and shell subregions, which have been most extensively studied, show striking differences in their afferent input and efferent projections (Heimer et al., 1991; Zahm \& Brog, 1992). For example, although both the core and the shell receive input from the hippocampus, the ventral subiculum projects exclusively to the shell, whereas the dorsal subiculum projects to the core. Different regions of the prefrontal cortex project to different zones; the prelimbic area projects to the core, whereas the infralimbic and piriform cortices project to the shell (Brog et al., 1993). Specific subcompartments of the amygdala also reach distinct subregions within the accumbens core and shell (Wright, Beijer, \& Groenewegen, 1996). In terms of outputs, the core subregion connects extensively to classic basal ganglia output structures, such as the ventral pallidum, the subthalamic nucleus, and the substantia nigra. The shell subregion, in contrast, projects preferentially to subcortical limbic regions, such as the lateral hypothalamus, the ventral tegmental area, the ventromedial ventral pallidum, and brainstem autonomic centers.

It should further be noted that there are distinct histochemical features that also characterize the core and shell subregions (Groenewegen, Wright, \& Beijer, 1996). One of the most clear markers is immunoreactive staining for the calcium-binding protein calbindin, which is heavily concentrated in the core and the caudate-putamen but is virtually absent in the shell, at least in the rat. Another delineating marker is substance $\mathrm{P}$ immunoreactivity, which lightly stains the core, more densely stains the shell, and very densely stains regions of the ventral pallidum that are found just ventral to the shell. The medial shell also stains more densely for dopamine-like immunoreactivity and acetylcholinesterase (Alheid \& Heimer, 1988; Voorn, Jorritsma-Byham, Van Dijk, \& Buijs, 1986).

On the basis of these distinctive anatomical profiles, it has been proposed that there may be significant functional specializations of these two subregions and their associated circuitry (Deutch \& Cameron, 1992; Heimer et al., 1991; Zahm \& Brog, 1992). The general notion is that the accumbens core has similarities to the overlying caudate-putamen and may be more allied with voluntary motor functions, whereas the shell has close ties to the extended amygdala (Alheid \& Heimer, 1988) and its functions are more in the domain of visceral or motivational mechanisms. In this paper, evidence is presented in support of this general hypothesis. Moreover, this hypothesis is further extended to state that the core of the accum- 
bens and, particularly, $N$-methyl-D-aspartate (NMDA) receptors in this region are critical for instrumental learning, whereas the shell of the accumbens and, particularly, gamma-amino butyric acid (GABA) and alpha-amino-3hydroxy-5-methylisoxazole-4-propionic acid (AMPA) receptors are specifically involved in the control of feeding. A summary of the input and output relationships of the accumbens core and shell, with their respective proposed functions, is diagramed in Figure 1.

\section{Glutamate Receptors Within the Nucleus Accumbens Core: A Forebrain Mechanism for Appetitive Instrumental Learning}

Given the long association of the nucleus accumbens with motivation and reward, it is not surprising that many studies have focused on the role of this structure in learning and memory. Earlier studies particularly focused on the role of ventral striatal dopamine in rewardrelated learning (Beninger, 1983), and a number of experiments utilizing 6-OHDA lesions or pharmacological manipulations suggested that blockade of DA disrupted learning (Beninger \& Phillips, 1980; Taylor \& Robbins, 1986) and enhancement of DA facilitated learning (Robbins, 1978; Taylor \& Robbins, 1984). However, it is often difficult to clearly interpret DA manipulations, since they nearly always affect response output or performance. Work with electrolytic or selective excitotoxic lesions has also indicated a role for the nucleus accumbens in learning; for example, such lesions impair acquisition of learning in the Morris water maze (Sutherland \& Rodriguez, 1989), spatial discrimination in a T-maze (Annett, McGregor, \& Robbins, 1989), and a visual S-R task (Reading, Dunnett, \& Robbins, 1991). Several recent studies employing lidocaine-induced inactivation of the accumbens have provided further evidence for this structure mediating certain aspects of spatial learning and performance (Floresco, Seamans, \& Phillips, 1996, 1997). The role of the nucleus accumbens in learning and memory and, particularly, the influence of hippocampal input have been the subject of a recent review (Setlow, 1997).

Within the framework initiated by Mogenson, much thought has been given over the past decade or so to the role of glutamate-coded inputs to the nucleus accumbens. As in the overlying caudate nucleus, the mediumsized spiny output neurons, which make up the main cellular component of these structures, receive excitatory input in the form of glutamate (Fonnum, 1984; P. L. McGeer, E. G. McGeer, Scherer, \& Singh, 1977). Moreover, there are high levels of all glutamate receptor subtypes in the striatum (Albin et al., 1992). As was noted in the previous section, the area including the nucleus accumbens is particularly distinctive in that it receives strikingly convergent inputs from the hippocampus, prefrontal cortex, amygdala, midbrain, and thalamus and, in
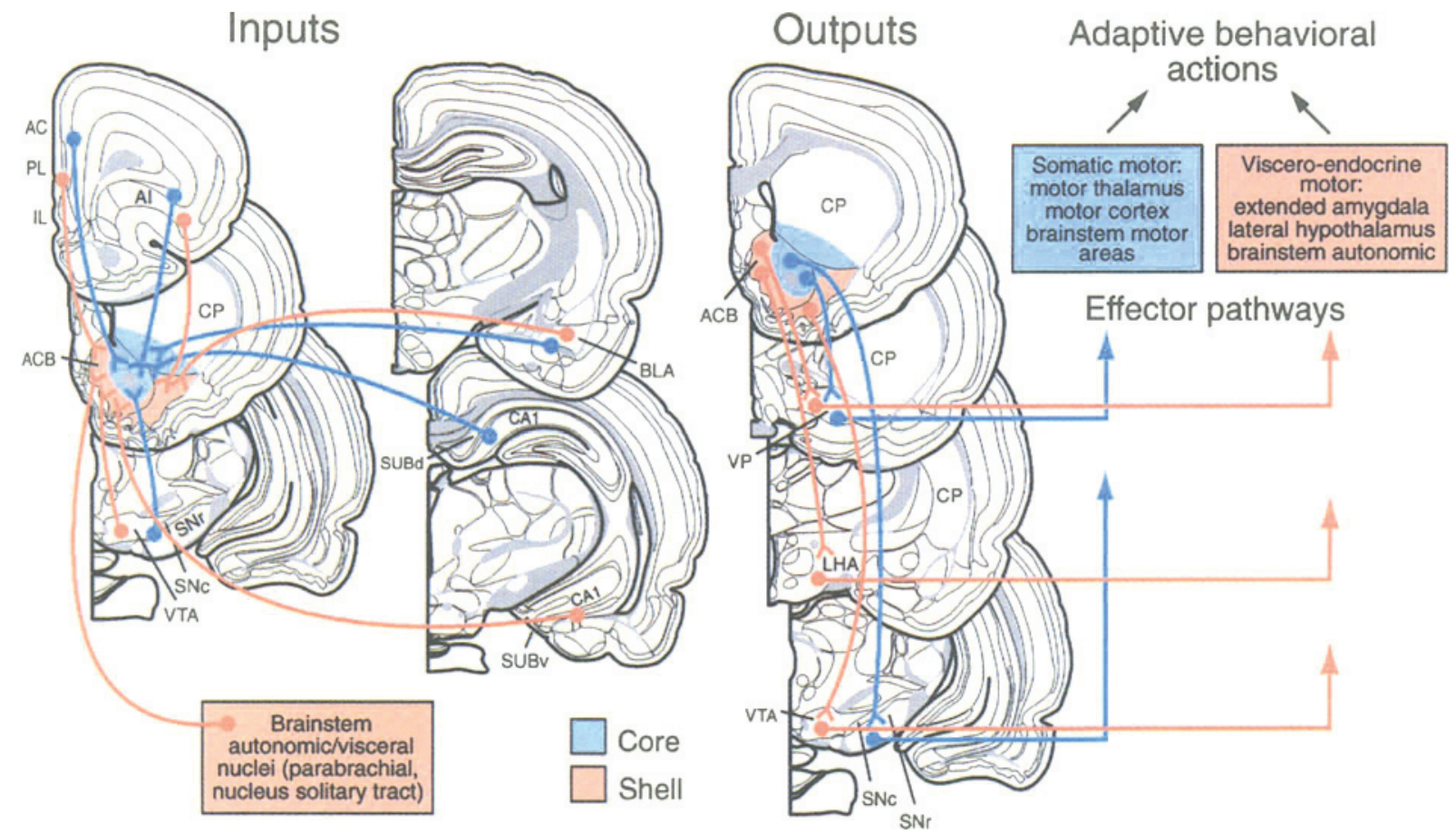

Figure 1. Organization of ventral striatal circuitry suggests an integrative role in adaptive motor actions, as is discussed in the text. Major input and output pathways are emphasized, although not all connections are shown. Abbreviations: $\mathrm{AC}$, anterior cingulate; ACB, accumbens; AI, anterior insular cortex; BLA, basolateral amygdala; CP, caudate-putamen; IL, infralimbic cortex; LHA, lateral hypothalamic area; PL, prelimbic cortex; SUBd, dorsal subiculum; SUBv, ventral subiculum; SNc, substantia nigra, pars compacta; SNr, substantia nigra, pars reticulata; VP, ventral pallidum; VTA, ventral tegmental area. 
turn, projects to both somatic and visceral motor output systems. Recently, our research has focused on the investigation of functions of the nucleus accumbens and its related circuitry through the study of its glutamatergic innervation. Our first studies showed that blockade of NMDA receptors within the core of the accumbens (but not within the shell) reduced exploratory locomotion (Maldonado-Irizarry \& Kelley, 1994), a result similar to that of previous work conducted with nonselective glutamate antagonists (Mogenson \& Nielsen, 1984). We then conducted several studies utilizing NMDA antagonist infusion into accumbens subregions on learning in several spatial tasks. Local infusion of the selective competitive antagonist AP-5 into the core was found to severely disrupt path learning in a spatial food-gathering task (Maldonado-Irizarry \& Kelley, 1995). Infusion of the selective AMPA/kainate antagonist DNQX (6,7dinitroquinoxaline-2,3-dione) into the core mildly impaired learning, and both drugs had lesser effects when infused into the shell. In a recent study of the effect of striatal infusion of AP-5 in an eight-arm radial arm maze (with four arms baited), blockade of NMDA receptors in the accumbens core, but not in the shell, markedly disrupted acquisition of efficient responding (Smith-Roe, Sadeghian, \& Kelley, in press). Once the animals had learned the task, however, AP-5 infusion into the core had no effect.

Although it was clear that NMDA receptors were involved in spatial learning, we were curious whether other forms of learning would be affected by intra-accumbens NMDA blockade. In one series of experiments, the consequences of intra-accumbens infusion of AP-5 on acquisition of a leverpress task for food were investigated (Kelley, Smith-Roe, \& Holahan, 1997). In this task, hungry animals are exposed in an operant chamber to two levers, one of which provides a food pellet when pressed, for a 15-min session on a fixed-ratio 2 schedule. Normal rats learn this task quite rapidly over days. Somewhat to our surprise, rats treated with AP-5 in the core showed no learning whatsoever and only began to learn the task when infusions were no longer given (see Figure 2). Equivalent infusions in the accumbens shell had little effect on response learning. Parallel experiments examining the effects of these treatments on general motor behavior and feeding indicated that the impairment could not be attributed to a general motor or motivational deficit. Moreover, AP-5 had no effect once the animals had learned the task, suggesting that, as for the spatial-learning experiments, NMDA-dependent mechanisms are critical only in the early stages of learning.

These results are among the first demonstrating NMDA-dependent mechanisms in striatal-based learning. Of course, there is much evidence for a major role of basal ganglia structures in motor learning. Several earlier postulates suggested a role for striatal systems in cognitive and affective functions, in addition to their well-known motoric functions (Alexander, DeLong, \& Strick, 1986; Divac, 1972). A considerable array of em-
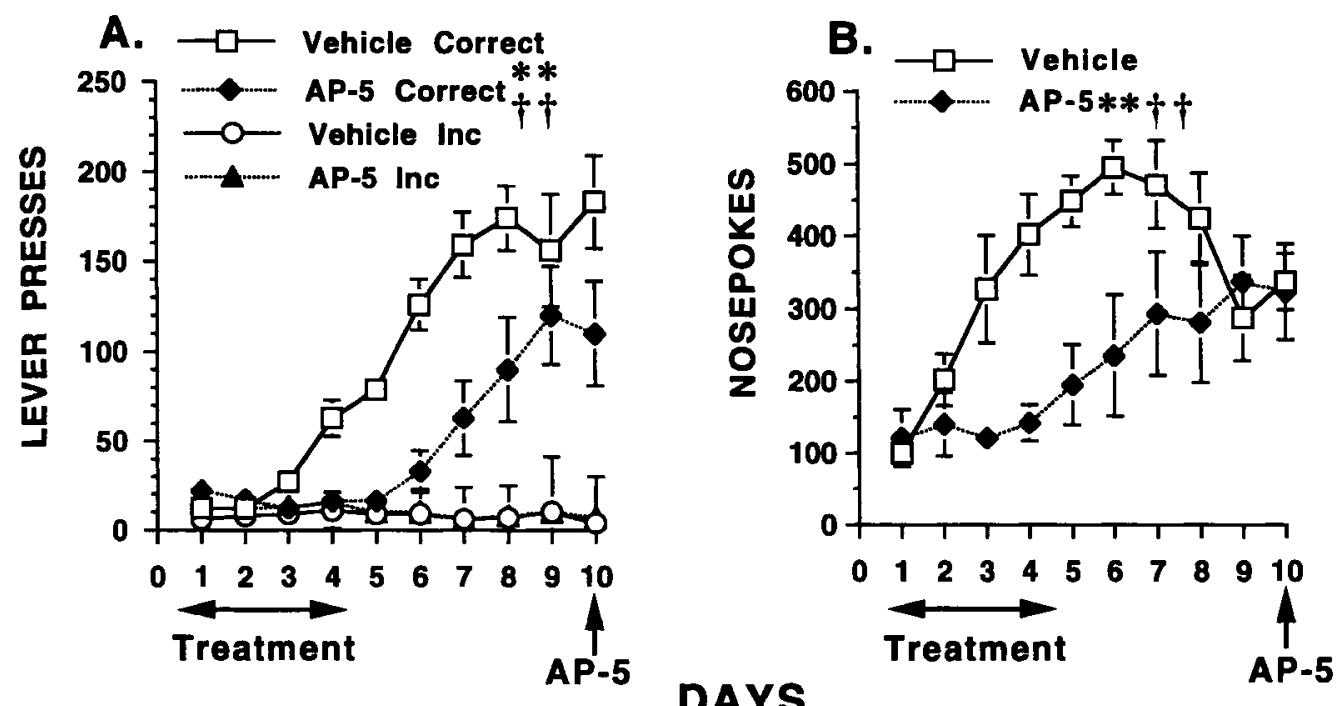

\footnotetext{
Figure 2. Appetitive instrumental learning is dependent on $\mathbf{N}$-methyl-D-aspartate (NMDA) receptor activation in the nucleus accumbens core. Panel $A$, acquisition of a leverpress response for food over time; panel B, nose-poking behavior into food tray during learning. Animals were injected in the nucleus accumbens core with the NMDA antagonist AP-5 ( 5 nmol, bilaterally) or vehicle (saline) before the first four sessions and then were tested without treatment for 5 days. On Day 10, all the rats (including the vehicle group) received AP-5. Asterisks indicate overall treatment effects in an analysis of variance; daggers indicate treatment $\times$ day interactions. From "Response-Reinforcement Learning Is Dependent on NMDA Receptor Activation in the Nucleus Accumbens Core," by A. E. Kelley, S. Smith-Roe, and M. R. Holahan, 1997, Proceedings of the National Academy of Sciences, 94, p. 12176. Copyright 1997 by the National Academy of Sciences. Reprinted with permission.
} 
pirical data supports the contention that both ventral and dorsal striatal regions are important for certain forms of learning. One prominent theory holds that the striatum is crucial for the acquisition of relatively automatic motor habits, or basic S-R associative learning (R. J. McDonald \& White, 1993; Mishkin \& Petri, 1984; Packard \& McGaugh, 1992), in contrast to the hippocampus and amygdala, which are generally thought to be more involved in contextual or declarative learning and in stimulusreward learning. In other words, returning to Thorndike's law of effect, a key neural mechanism must exist whereby a response followed by satisfaction becomes strengthened, and the probability of its occurrence becomes greatly facilitated in the appropriate stimulus conditions. Whereas most work in this domain has implicated the caudate (dorsal striatum), it appears that the accumbens core may also play an important role. (This idea is in accordance with the notion that the accumbens core has certain functional and connectional similarities to the caudate, as was discussed above.) More specifically, we propose that activation of NMDA receptors in the accumbens core, together with concomitant intracellular molecular events, is such an essential mechanism for adaptive response learning. (Whether this theory applies to both appetitive and aversive motor learning, as well as to both the dorsal and the ventral striatum, is not yet certain.) It should be noted, moreover, that other aspects of learning may also be mediated by the accumbens core; for example, it has recently been shown that excitotoxic lesions of the core (but not of the shell) impair the learning of anticipatory approach response governed by a Pavlovian conditioned stimulus (CS; Parkinson, Olmstead, Burns, Robbins, \& Everitt, 1999); we have shown a similar impairment with intracore AP-5 infusions (Kelley, Smith-Roe, \& Holahan, 1997). Thus, the control of CSUCS (unconditioned stimulus) associations over learned behavior may also depend on accumbens core neurons and, in particular, on input from the basolateral amygdala (Cador, Robbins, \& Everitt, 1989; Everitt, Cador, \& Robbins, 1989). It should be further emphasized that it is likely that structures other than the accumbens core participate in adaptive motor learning. Indeed, our recent studies suggest that NMDA-receptor-dependent plasticity within a distributed network involving the amygdala and the prefrontal cortex, as well as the accumbens core, underlies appetitive motor learning (Baldwin, Holahan, Sadeghian, \& Kelley, 1999). However, at this juncture, it is premature to speculate about precisely which aspects of instrumental learning (i.e., stimulus-reward or rewardresponse associations, response selection, attention, etc.) each of these structures mediates.

\section{Neuronal Plasticity in the Ventral Striatum}

There is much empirical evidence to support this hypothesis of neuronal plasticity, which has emerged relatively recently. Although classic work on neuronal plasticity in relation to learning and memory has focused primarily on the hippocampus, in recent years data have accrued supporting plasticity within the striatum and the accumbens, at both the cellular and the molecular level. First, striatal neurons are involved in assessing, learning, and responding to stimuli with motivationally significant valence. For example, neurons in the monkey ventral and dorsal striatum are sensitive to both primary and conditioned rewards (Aosaki, Graybiel, \& Kimura, 1994; Apicella, Scarnati, Ljungberg, \& Schultz, 1992; Bowman, Aigner, \& Richmond, 1996). Moreover, during acquisition of sensorimotor conditioning in monkeys, in which a cue predicts delivery of a juice reward, a progressive increase in the number of tonically active neurons that respond to that cue emerges (Aosaki, Tsubokawa, et al., 1994). Examples of cellular plasticity, such as long-term potentiation and long-term depression, have been demonstrated in both the dorsal striatum and the accumbens (Boeijinga, Mulder, Pennartz, Manshanden, \& Lopes da Silva, 1993; Calabresi, Pisani, Mercuri, \& Bernardi, 1996; Kombian \& Malenka, 1994; Lovinger, Tyler, \& Merritt, 1993; Uno \& Ozawa, 1991). For example, tetanic stimulation of prefrontal efferents induces NMDA-dependent long-term potentiation (LTP) in the nucleus accumbens (Pennartz, Ameerun, Groenewegen, \& Lopes da Silva, 1993). A recent study reported simultaneous induction of LTP within the accumbens and the prefrontal cortex following stimulation of the fornix-fimbria bundle (Mulder et al., 1997), suggesting that the accumbens may be part of a distributed network participating in memory formation. Indeed, several recent neural network models incorporate the hippocampal-accumbens pathway as a mechanism for successful selection or "stamping in" of correct locomotor actions (M. A. Brown \& Sharp, 1995; Redish \& Touretsky, 1997).

It is important to consider what the role of dopamine might be in this model. A current influential theory posits that activity in dopaminergic neurons serves as a predictor of reward or stimulus salience (Schultz, Dayan, \& Montague, 1997). Dopamine neurons alter their firing properties during learning; initially, they are activated by primary rewards, but if a stimulus consistently predictive of reward is presented over trials (CS), there is a progressive shift in firing pattern in such a way that the activation is observed only in response to presentation of the CS, but no longer to presentation of the primary reward (Schultz, Apicella, \& Ljungberg, 1993). Thus, midbrain dopamine neurons, which project to widespread cortical and striatal areas, are proposed to "construct and distribute information about rewarding events" (Schultz et al., 1997). In relation to the present hypotheses concerning accumbens NMDA receptors, glutamate-dopamine interactions may initiate a cascade of biochemical events that eventually leads to alterations in gene expression and that would ultimately influence long-term or permanent synaptic changes underlying motor learning. Indeed, several recent theoretical models have been proposed to explain reinforcement learning in corticostriatal systems. These models postulate an interaction of dopaminergic and corticostriatal synapses, and consequent integrated 
molecular signals, on the dendritic spines of striatal medium-sized spiny output neurons (Houk et al., 1995; Houk \& Wise, 1995; Kötter, 1994; Wickens \& Kötter, 1995). Dopaminergic and glutamatergic inputs synapse in close proximity on the same dendritic spine (Smith \& Bolam, 1990). Activity in spiny neurons is largely dependent on excitatory input from the cortex. Influx of calcium via NMDA receptors in association with dopaminemediated intracellular changes (such as in the cAMP system) is proposed as being essential for the cellular basis of reinforcement. The demonstration of long-term enhancement of synaptic strength when cortical striatal excitation and dopaminergic activation are temporally coordinated supports this notion (Wickens, Begg, \& Arbuthnott, 1996), and it has also been found that dopamine selectively enhances NMDA-induced excitations in striatal slices (Cepeda, Buchwald, \& Levine, 1993). Thus, it is possible that enhanced dopaminergic activity at a site on the dendritic spine would promote or facilitate the NMDAmediated synaptic changes necessary for learning. Protein phosphorylation may also play an integral role in this process; for example, we have recently found that intra- accumbens infusions of protein kinase $A$ inhibitors impair instrumental learning in the paradigm described above (Kelley, Holahan, Smith-Roe, \& Baldwin, 1997). These putative mechanisms are diagramed in Figure 3.

Additional evidence for activity-dependent plasticity with the striatum derives from accumulating evidence that drugs of abuse have profound effects on transcription factors and gene expression. Amphetamine, cocaine, and morphine rapidly induce expression of the nuclear immediate early genes, such as $c$-fos, $c$-jun, fos $B$, junB, Fras, and zif/268 (Graybiel, Moratalla, \& Robertson, 1990; Hope, Kosofsky, Hyman, \& Nestler, 1992; Wang \& McGinty, 1995; Wang, Smith, \& McGinty, 1995), and can alter transcription factors, such as the expression of phosphorylated CREB (cyclic AMP response-elementbinding protein), AP-1 binding (protein binding to DNA response elements), and peptide gene expression (Hope et al., 1992; Simpson, Wang, \& McGinty, 1995; Wang, Daunais, \& McGinty, 1994). Moreover, there is evidence for adaptations in expression of these factors with chronic treatment, as compared with acute effects (Daunais \& McGinty, 1994; Hope et al., 1992; Simpson et al., 1995).

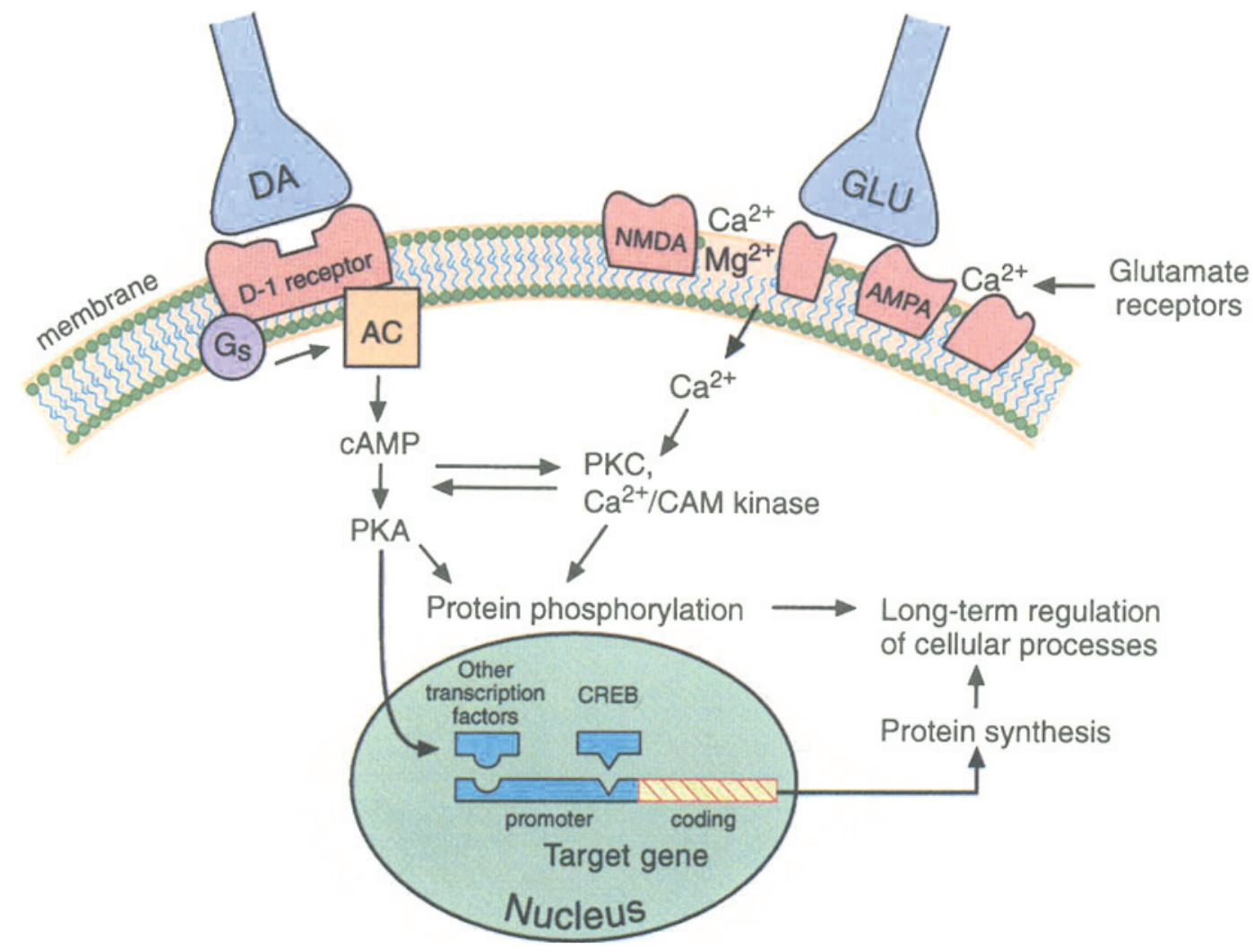

Figure 3. A schematic model of neural plasticity within the dendritic spines of ventral striatal medium spiny neurons. Glutamate-dopamine interactions within the core region of the nucleus accumbens (and, perhaps, other striatal regions) may initiate a cascade of biochemical events that lead to alterations in signal transduction and gene expression, effecting long-term or permanent synaptic changes underlying motor learning. Dopaminergic inputs from the midbrain and glutamatergic inputs from the cortical, limbic, and thalamic regions synapse in close proximity on the same dendritic spine. 
It is also been shown that animals self-administering drugs of abuse show altered levels of striatal and accumbens gene expression (Daunais, Roberts, \& McGinty, 1995; Pich et al., 1997). It is noteworthy that many of these effects appear to be dependent on either NMDA or dopamine D-1 receptor activation. For example, pretreatment with MK-801, an NMDA antagonist, or the D-1 antagonist SCH-23390 prevents amphetamine induction of c-fos and zif/268 (Konradi, Leveque, \& Hyman, 1996; Wang et al., 1994), and the fos and jun mRNA induction by D-1 agonists or dopamine in dissociated striatal cultures is blocked by both competitive and noncompetitive NMDA antagonists (Konradi et al., 1996). Behavioral sensitization to psychostimulants is also prevented by MK801 (Wolf, White, \& $\mathrm{Hu}, 1994$ ). Thus, there is convincing evidence to suggest that plasticity-related neuroadaptations within the ventral striatum and related circuitry may depend on glutamate-dopamine interactions. Most significantly, the neuroadaptations that are concomitants of learning may also underlie the process of addiction. In other words, the neuromolecular effects of addictive drugs appear to mimic the brain's normal mechanisms for ensuring appetitive learning.

\section{The Nucleus Accumbens Shell: \\ A Central Integrator of Feeding}

One of the most intriguing findings in the past decade concerning the nucleus accumbens is the clear distinction between the core and the shell subregions, as was discussed above. In fact, by virtue of the core being placed quite centrally within the nucleus accumbens, until rather recently most studies focused on what became known as the core. That is, the region at which most investigators placed their lesion, stimulation, microinfusion, or dialysis probes tended to be the central accumbens. Although there are several earlier reports using stereotaxic coordinates that were aimed at the medial accumbens (Mogenson, Swanson, \& Wu, 1983), until quite recently it remained more or less a terra incognita. In particular, very little, if any, attention was given to the very posterior, medial aspects of the accumbens that have been termed the septal pole. The first suggestion that the shell might be involved in basic motivational drives arose from the theory that it was part of a forebrain system known as the extended amygdala, which includes the central and medial amygdala and the bed nucleus of the stria terminalis (Alheid \& Heimer, 1988; Heimer, Alheid, \& Zahm, 1993 ) and which has prolific outputs to brainstem autonomic and locomotor areas. Recent studies with very discrete injections of retrograde or anterograde tracers show connections, either monosynaptically or indirectly via the pallidum and the hypothalamus, to widespread brainstem circuits involved in autonomic arousal, neuroendocrine regulation, consummatory behaviors, pain modulation, and defensive behaviors (e.g., central gray, mesopontine tegmentum, nucleus of solitary tract; Groenewegen et al., 1996; Heimer et al., 1991).

In the course of our studies on the role of the accumbens glutamate in exploratory and spatial behavior, we have found that manipulations of the shell seemed to have little or no effect in the learning paradigms. This was initially somewhat surprising, since we had originally hypothesized that the medial accumbens would be preferentially involved in exploration and learning owing to its strong hippocampal input. In fact, it was entirely due to serendipity that we noticed animals voraciously feeding when they were put back in their home cages, following blockade of AMPA/kainate receptors in the shell with the drug 6,7-dinitroquinoxaline-2,3-dione (DNQX). This effect was systematically examined, and we reported that blockade of AMPA/kainate receptors within the shell, but not within the core, induced marked and prolonged feeding in satiated rats (Maldonado-Irizarry, Swanson, \& Kelley, 1995). This feeding has an extremely short onset latency (20-40 sec, approximately) and is not elicited by the infusion of NMDA antagonists. Further work showed that the effect is not blocked by naltrexone but is reduced by systemic administration of both D-1 and D-2 antagonists. A detailed mapping study of the ventral and dorsal striatum showed an even greater degree of anatomical specificity; feeding was only elicited from the accumbens shell, and the posterior aspects of the shell were more sensitive than the anterior aspects (Kelley \& Swanson, 1998). This is an interesting finding, because it suggests that cells within the more posterior shell, which is more strongly connected to viscero-endocrine circuits, are preferentially involved in feeding. A study investigating the behavioral specificity of the DNQX effect found that water intake and wood-chip gnawing were not affected; however, palatable sucrose solution intake was increased by the treatment (Stratford, Swanson, \& Kelley, 1998). The feeding response bore remarkable resemblance to electrically induced feeding from the lateral hypothalamus $(\mathrm{LH})$, and we tested the hypothesis that activation of the LH is critical for the feeding effect. Indeed, this effect is blocked by concurrent inactivation of the $\mathrm{LH}$ with muscimol, suggesting that the ingestive behavior is mediated through activation of cells within the LH. This was a novel demonstration of a specific behavioral role for the accumbens shell and suggested an important functional link between two major brain regions involved in reward, the accumbens and the lateral hypothalamus.

If the theory that removal of an excitatory input caused feeding were correct, we speculated that direct inhibition of the cells would also induce feeding. We found that infusion of muscimol, the $\mathrm{GABA}_{\mathrm{A}}$ agonist, or baclofen, the GABA $_{B}$ agonist, both caused intense feeding in satiated rats when infused into the accumbens shell (Stratford \& Kelley, 1997b). As for DNQX, the effect was also specific for feeding (water intake was not affected). A mapping study confirmed that the posterior shell was most sensitive to feeding (Basso \& Kelley, 1999), and a pharmacological double dissociation was shown (the $\mathrm{GABA}_{\mathrm{A}}$ effect was blocked by $\mathrm{GABA}_{\mathrm{A}}$ antagonists but not by $\mathrm{GABA}_{B}$ antagonists, and vice versa). A compound that causes increases in endogenous GABA, gamma-vinylGABA, by inhibiting GABA-transaminase, also markedly increased feeding. These findings suggest that the 
medium spiny neurons within the shell, which contain GABA as their major transmitter, may release GABA to activate normal feeding, which by self-inhibition (through recurrent collaterals) would result in disinhibition of $\mathrm{LH}$ or, perhaps, other downstream cells involved in feeding. We have recent evidence supporting this hypothesis. Utilizing expression of the immediate early gene $c$-fos as a marker for neuronal activation, we found that intrashell muscimol markedly activates Fos expression throughout the LH, as is shown in Figure 4 (Stratford \& Kelley, 1997a), and when LH cells are activated by glutamate agonists, feeding also occurs (Stanley, Willet, Donias, Ha, \& Spears, 1993). Also, the $\mathrm{GABA}_{\mathrm{B}}$ effect is interesting, because $\mathrm{GABA}_{\mathrm{B}}$ receptors are nearly universally presynaptic and it has been shown that baclofen inhibits glutamate release in the nucleus accumbens (Uchimura \& North, 1991). Thus, if glutamate terminals have presynaptic
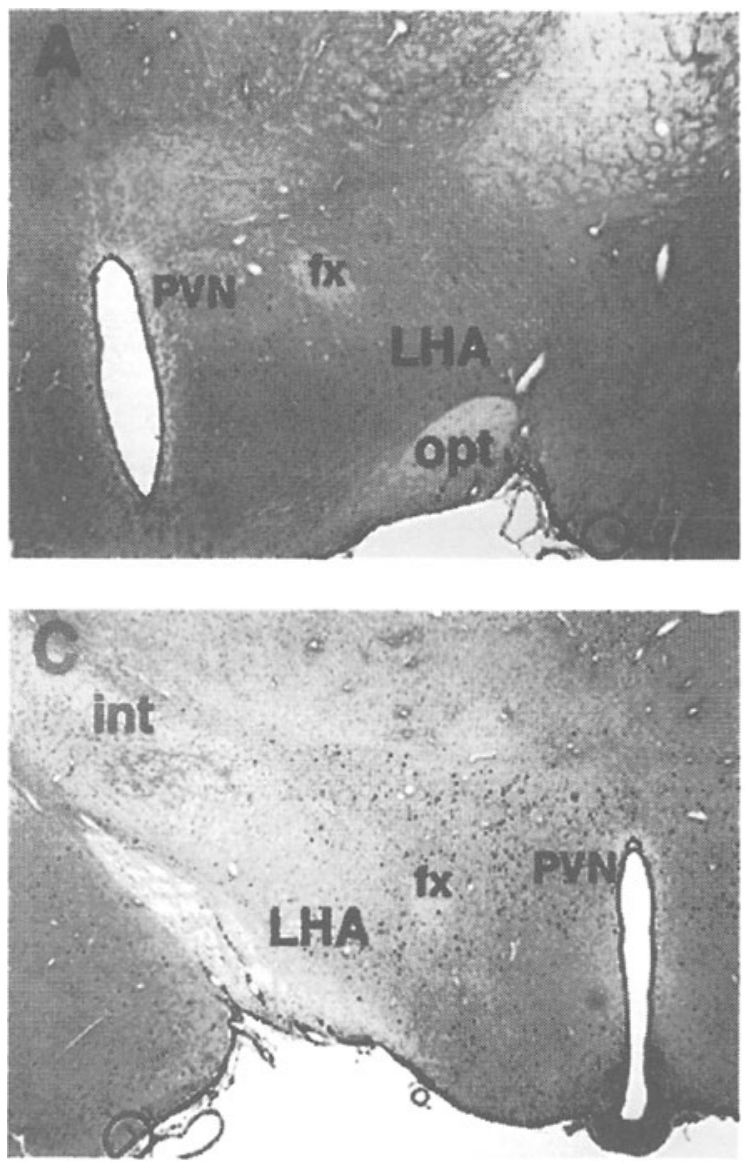

$\mathrm{GABA}_{\mathrm{B}}$ receptors, this could be an additional mechanism by which the glutamate input is attenuated during feeding.

A tentative model regarding the mechanisms underlying the feeding response is diagramed in Figure 5. Certain neural inputs may normally exert a tonic excitatory effect on shell neurons, via non-NMDA (AMPA or kainate) receptors. Temporary removal of this excitation with DNQX causes shell neurons to become inactive, thereby disinhibiting intrinsic LH neurons and causing animals to eat. A basic assumption of the model is that neurons arising in the shell exert an inhibitory influence on lateral hypothalamic neurons, via a GABAergic mechanism. Evidence for an inhibitory pathway from the medial accumbens to the lateral hypothalamus has been demonstrated (Mogenson et al., 1983). However, it should be emphasized that that shell-LH interaction may be mediated via an indirect pathway, rather than a direct one.
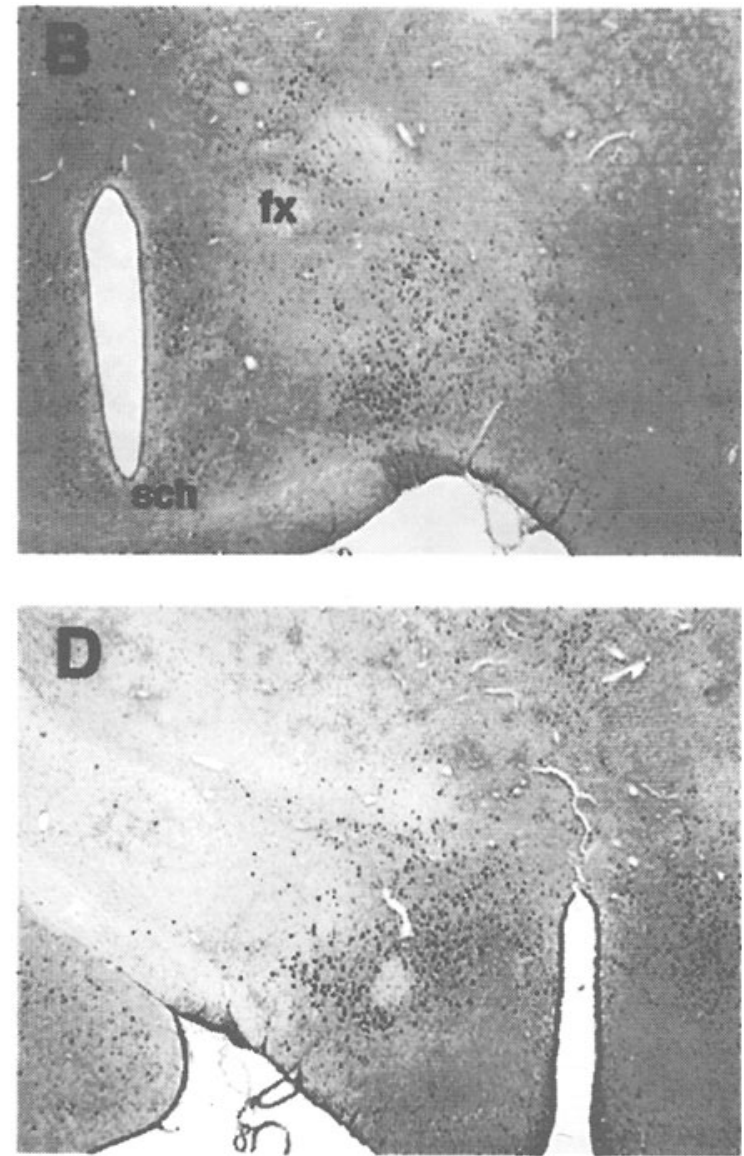

Figure 4. Expression of the immediate early gene $c$-fos in the hypothalamus following infusion of the $\mathbf{G A B A}_{\mathrm{A}}$ agonist muscimol $(50 \mathrm{ng})$ into the nucleus accumbens shell. $A$ and $C$ are vehicle-treated animals; $B$ and $D$ are muscimol-treated animals. Food and water were not available following treatment; animals were perfused 90 min following treatment, and the brains were processed for immunocytochemical detection of Fos protein. Note the strong expression in the muscimol-treated rats in the lateral hypothalamus; some expression was also observed in the periventricular nucleus. Abbreviations: PVN, periventricular nucleus of hypothalamus; fx, fornix; LHA, lateral hypothalamic area; opt, optic tract; sch, suprachiasmatic nucleus; int, internal capsule. (Based on work from Stratford \& Kelley, 1997a.) 


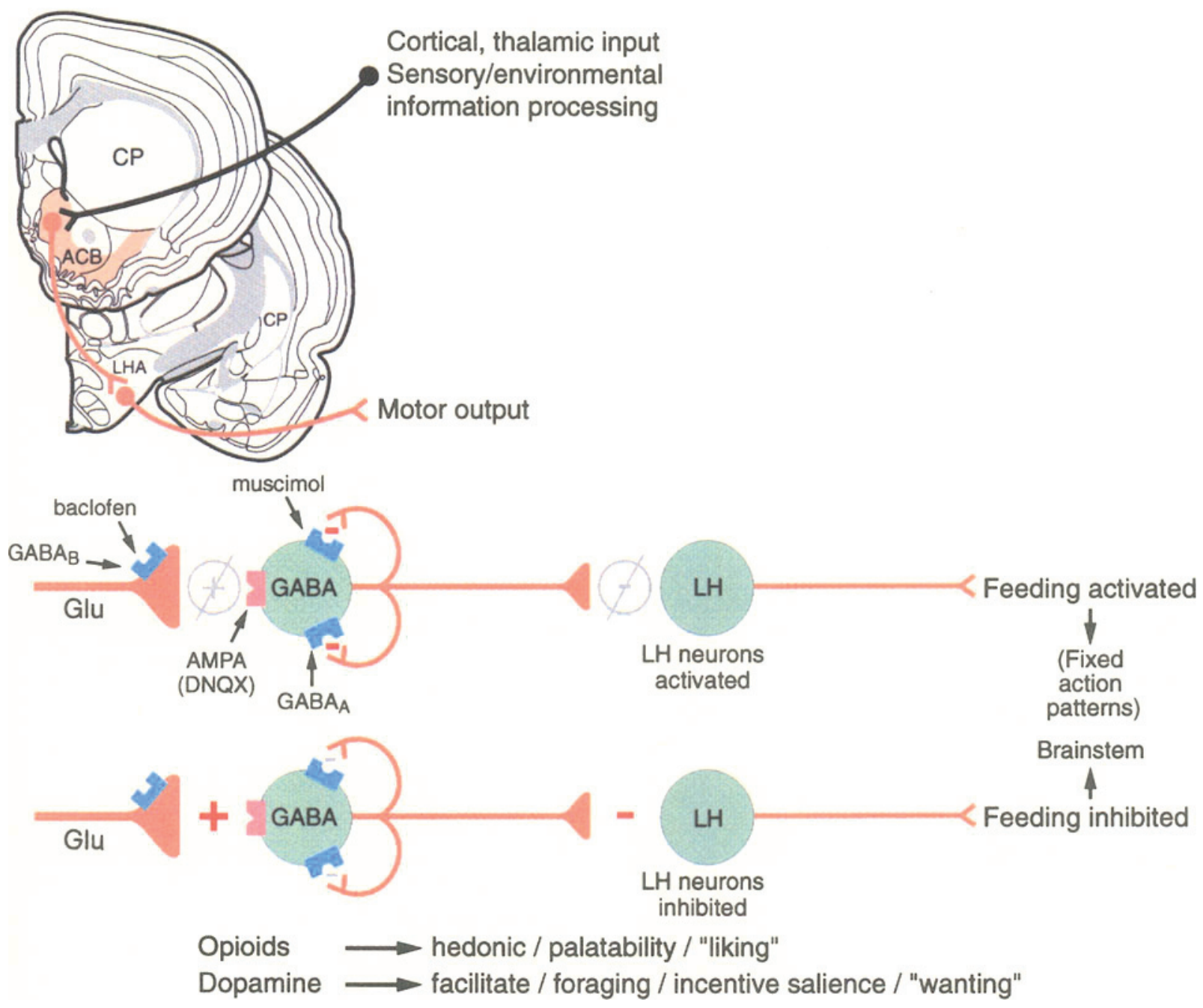

Figure 5. A proposed model of ventral striatal integration of feeding behavior, as is discussed in the text. Neurotransmitter interactions are proposed to take place within the shell subregion of the nucleus accumbens. Medium spiny output neurons within the shell

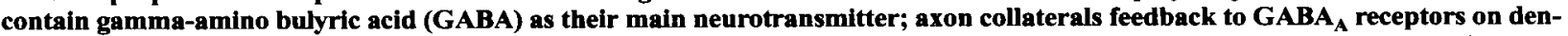
drites in these neurons and also to the dendrites on neighboring neurons (not shown). Cortical and thalamic input reaches spiny neurons via glutamatergic projection; these glutamatergic terminals may contain $G_{A B A}$ receptors as-well. Increased inhibition of these neurons removes the tonic inhibition on lateral hypothalamic (LH) neurons, causing activation of LH neurons and feeding to occur. Blockade of AMPA receptors (via the antagonist DNQX) also lowers activity of shell spiny neurons and results in feeding. It is proposed that phasic glutamate release (perhaps resulting from novel sensory or environmental processing) may overcome GABA-mediated inhibition, cause an override of the feeding signal, and switch behavioral patterning away from feeding, if it is adaptive to do so. It is further speculated that opioids within the ventral striatum may modulate palatability or hedonic evaluation of food (“liking," in the model of Robinson \& Berridge, 1993), whereas dopamine has a facilitory role in promoting motor responses that enable the animal to come in contact with food and signaling incentive state ("wanting", in the Robinson \& Berridge model).

Moreover, it is not certain whether the shell as a region has an exclusive role in feeding or whether it is ensembles of distinct neurons within the region, or a specific neurotransmitter code, that control behavioral specificity. This idea is discussed further below.

In addition, mention should be made of opioid modulation of feeding within the ventral striatum, although it is not the primary focus of this review. We have found that mu opioid stimulation of the nucleus accumbens results in considerable enhancement of food intake, par- ticularly of highly palatable foods such as fat, sucrose, and salt (Zhang, Gosnell, \& Kelley, 1998; Zhang \& Kelley, 1997). In contrast to the muscimol results, this effect is not specific to the medial shell and is found throughout the ventral striatum, with the lateral shell being the most sensitive part (Zhang \& Kelley, 1998). Intra-accumbens opioid injection also activates Fos expression in several hypothalamic regions, as well as in the nucleus of the solitary tract (unpublished findings), even without food being present, suggesting that this forebrain system has 
direct effects on lower brainstem areas involved in ingestion. These data suggest that opioid peptides within the accumbens shell may play a specific role in palatability and may also interact with the amino-acid-coded systems controlling food intake in this region.

\section{Interactions Between Appetitive and Aversive Stimuli in the Accumbens Shell}

Although our work clearly demonstrates a role for GABAergic accumbens shell neurons in feeding, there nevertheless remain some puzzling facts. For example, the dopamine turnover or activation in the shell is very sensitive to a variety of stress procedures (Deutch \& Cameron, 1992; Horger, Elsworth, \& Roth, 1995; Kalivas \& Duffy, 1995; King \& Finlay, 1997; Tidey \& Miczek, 1996), and expression of $c$-fos is most apparent in the shell, rather than in the core, with exposure to conditioned fear (Beck \& Fibiger, 1995). However, paradoxically, the shell is very sensitive to reward-related effects as well. We have found in our own material that expression of Fos in the shell is activated by both stressful and reinforcing stimuli (unpublished findings). Drugs of abuse tend to activate dopamine preferentially in the shell, as compared with the core (Pontieri, Tanda, \& Di Chiara, 1995; Pontieri, Tanda, Orzi, \& Di Chiara, 1996), and microinjections of D-1 dopamine antagonists into the shell reduce the reinforcing effects of intravenous cocaine (Caine, Heinrichs, Coffin, \& Koob, 1995). Certain drugs of abuse are preferentially administered to the shell, as compared with the core (Carlezon, Devine, \& Wise, 1995; Carlezon \& Wise, 1996). The shell, therefore, may have a role in regulating both appetitive and aversively motivated behavior. An important question concerns how these two possible functions interact. One interesting conjecture, based on analysis of distinct input-output relationships, is that there may be distinct neuronal ensembles within the nucleus accumbens, which suggests even further specialized compartmentalization beyond simply the core and the shell (Wright et al., 1996; Wright \& Groenewegen, 1996). Combining tracing techniques with immunohistochemical staining, these authors have shown that very specific subregions of the amygdaloid complex reach specific subzones within the core and the shell of the accumbens and, furthermore, that the output of these zones is very distinct and segregated. Thus, it appears that limbic influences representing appetitive or aversive information could affect subensembles within the shell. O'Donnell (1999) has proposed that functional thalamo-cortical-striatal neuronal ensembles, encoding information via differential distributions of spatial and temporal activity, could convey specific cognitive information to the nucleus accumbens. Moreover, neurotransmitter influences may regulate the adaptive expression (or suppression) of reward- or stress-related behaviors. The shell is reported to have a substantial noradrenergic innervation (C. W. Berridge, Stratford, Foote, \& Kelley, 1997), and CRF and its receptors are also dense in this region (see Holahan, Kalin, \& Kelley, 1997). These two systems or their interaction could signal stress- or dangerrelated information to the nucleus accumbens.

It is of interest to consider the feeding model with regard to appetitive-aversive interactions and to pose the following question: Why have an accumbens shell, if the brain presumably already has several structures that control basic regulatory behaviors (the hypothalamus, the extended amygdala, brain stem regions, etc.)? As is depicted in Figure 5, gradual increases in endogenous GABA within the shell (perhaps regulated by circulating humoral factors, such as insulin or leptin) may be associated with increased motivation for food (along with changes in hypothalamic sensing systems). When a threshold level is met, feeding may be triggered, given that food is available. However, imagine a situation in which an animal is extremely hungry, finds food, and commences feeding. If a threat arises in the environment, feeding is immediately arrested, and the animal engages in appropriate behavior, such as fleeing, freezing, or fighting. Although there may be a considerable energy deficit and the motivation for food is strong, there must exist an immediate and powerful override of neural circuits controlling the feeding behavior. One brain region in which such a mechanism could occur is the accumbens shell. The convergence and rapid processing of glutamate-coded inputs from critical cortical regions processing external stimuli and contextual states (the ventral subiculum, the infralimbic prefrontal cortex, the amygdala) may be key in this regard. Phasic release of glutamate could reverse the hyperpolarization of the medium spiny neurons induced by GABA, resulting in a major switch in behavioral patterning. The ability to switch between behavioral repertoires has been attributed to the accumbens in other models (e.g., Evenden \& Carli, 1985; van den Bos, Charria Ortiz, \& Cools, 1992; Weiner, 1990), and such amino-acidcoded integration in the shell may strongly influence behavioral selection in response to changing environmental contingencies. Moreover, the shell's main operating units are striatal spiny neurons, which have among the highest convergence ratios in the nervous system and which possess unusual structural and functional properties that are ideally suited to context recognition and decision making (Houk \& Wise, 1995). Thus, the accumbens shell is unique, in that it is influenced by a complex superimposition of information from both the internal environment and the external world and its intrinsic neurons have unusual dendritic integrative properties.

\section{Dopamine in the Shell}

Dopamine in the shell does not appear to directly participate in triggering feeding. Although some feeding can be observed following dopaminergic stimulation of this region (Evans \& Vaccarino, 1986; Swanson, Heath, Stratford, \& Kelley, 1997), we have not found these small increases in intake to be comparable with that induced by GABAergic agonists or AMPA antagonists. It is gener- 
ally agreed that dopamine depletion or antagonism in the accumbens does not affect primary motivation for food. For example, 6-OHDA lesions of the accumbens do not affect taste reactivity (K. C. Berridge, Venier, \& Robinson, 1989), and local microinfusions of DA antagonists actually increase food intake in free-feeding situations, although they reduce motor activity (Bakshi \& Kelley, 1991). However, in several studies, it has been clearly demonstrated that extracellular accumbens dopamine is increased in hungry animals or rises with feeding (Bassareo, 1997; Hernandez \& Hoebel, 1988; Kiyatkin \& Gratton, 1994; Wilson, Nomikos, Collu, \& Fibiger, 1995). What, then, could be the role for dopamine in feeding? In accordance with the general hypothesis that dopamine signals availability of salient appetitive cues or rewards in the environment, it is likely that availability of food or contexts associated with food stimulate dopamine, which, consequently, may have a general activating effect on appetitively motivated behavior. In other words, dopamine is not specifically involved with controlling feeding circuits but rather is facilitory, as is proposed in many general theories of mesolimbic dopamine (e.g., Robbins \& Everitt, 1996; Robinson \& Berridge, 1993; Wise \& Rompré, 1989). Support for this notion is provided by a recent study reporting that extracellular dopamine increases in the shell of the accumbens when free-feeding animals are presented with a novel, highly palatable food; when the food is not novel, the dopamine response habituates (Bassareo, 1997). It is not yet clear whether dopamine has distinctive functions with regard to the core and the shell, and this question has not yet been adequately studied. However, a working hypothesis can be put forward on the basis of the general dissociation of functions expounded in this paper. Since the caudate nucleus and the accumbens core are the structures most clearly implicated in response learning, release of DA in these areas may facilitate NMDA-receptor-mediated learning. Concurrent release of DA in the accumbens shell is not involved in learning per se, but rather in signaling incentive salience and promoting motor responses that bring the animal in contact with a potentially rewarding stimulus. In a recent study, we found that the shell was generally much more sensitive to the locomotor stimulating effects of DA agonists than was the core. Therefore, DA in the shell may be involved in increasing the initial output of motor responses (that could potentially lead the organism to a rewarding stimulus), whereas DA in the core participates in the "stamping in" of those responses that led to a satisfactory outcome. In a recent study, excitotoxic shell lesions (but not those of the core) abolished the reward-enhancing and locomotor effects of amphetamine (Parkinson et al., 1999). This hypothesis does not exclude the possibility that dopaminergic stimulation of both the shell and the core is reinforcing by definition. In other words, it may be that rats would self-administer DA or dopaminergic agonists to both core and shell re- gions; this experiment has not been carried out to our knowledge.

\section{Conclusions}

Recent detailed anatomical findings have provided convincing evidence for the original major theory concerning the accumbens: that it acts as an integrator of internal and external sensory and motivationally relevant information with effector mechanisms, in order to ensure adaptive motor behavior. New research has allowed refinement of this theory. Our recent work and that of others has supported the general hypothesis that the core region is preferentially aligned with basal ganglia motor functions, whereas the role of the shell lies more in the domain of viscero-endocrine functions. It is proposed that NMDA receptors within the accumbens core are part of a neural network mediating appetitive instrumental learning. It is postulated that the shell is not involved in motor or response learning per se but is responsible for integrating basic drives and viscero-endocrine effector mechanisms with cortical and subcortical information processing. This dichotomy leads to a further fundamental question: How are these major functions integrated and coordinated? There is ample evidence provided through detailed analysis of circuitry, particularly with regard to patch-matrix configurations and microcompartmentalizations, that the subregions within the accumbens have extensive cross-talk, both locally and through open and feed-forward loops (Groenewegen et al., 1996; Pennartz, Groenewegen, \& Lopes da Silva, 1994). Joel and Weiner (1994) have suggested the idea of split loops with basal ganglia-thalamocortical circuitry, so that information from striatal subregions (limbic, associative, motor) can be integrated in the prefrontal cortex via overlapping projections to the substantia nigra, pars reticulata. The shell, which could be considered a striatal visceral area, has access to converging input from corticothalamic circuits and, in addition, has close access to responselearning mechanisms via the core and prefrontal output systems. Verification of these hypotheses awaits further experimentation utilizing integrated and multiple approaches. Nevertheless, it can be said with certainty that, in the 2 decades that have passed since Mogenson's hypothesis, encouraging progress has been made in understanding the pivotal role of the nucleus accumbens in learning and motivation.

\section{REFERENCES}

Albin, R. L., Makowiec, R. L., Hollingsworth, Z. R., Dure IV, L. S., Penney, J. B., \& Young, A. B. (1992). Excitatory amino acid binding sites in the basal ganglia of the rat: A quantitative autoradiographic study. Neuroscience, 46, 35-48.

Alexander, G. E., DeLong, M. R., \& Strick, P. L. (1986). Parallel organization of functionally segregated circuits linking basal ganglia and cortex. Annual Review of Neuroscience, 9, 357-381.

Alheid, G. F., \& Heimer, L. (1988). New perspectives in basal forebrain organization of special relevance for neuropsychiatric disorders: 
The striatopallidal, amygdaloid, and corticopetal components of substantia innominata. Neuroscience, 27, 1-39.

Annett, L. E., McGregor, A., \& Robins, T. W. (1989). The effects of ibotenic acid lesions of the nucleus accumbens on spatial learning and extinction in the rat. Behavioural Brain Research, 31, 231-242.

AosaKi, T., Graybiel, A. M., \& Kimura, M. (1994). Effect of the nigrostriatal dopamine system on acquired neural responses in the striatum of behaving monkeys. Science, 265, 412-415.

aosaki, T., Tsubokawa, H., Ishida, A., Watanabe, K., Graybiel, A. M., \& Kimura, M. (1994). Responses of tonically active neurons in the primate's striatum undergo systematic changes during behavioral sensorimotor conditioning. Journal of Neuroscience, 14, 3969-3984

Apicella, P., Scarnati, E., Luungberg, T., \& Schultz, W. (1992). Neuronal activity in the monkey striatum related to the expectation of predictable environmental events. Journal of Neurophysiology, 68 945-960.

BAKSHI, V. P., \& Kelley, A. E. (1991). Dopaminergic regulation of feeding behavior: I. Differential effects of haloperidol microinfusion into three striatal subregions. Psychobiology, 19, 223-232.

Baldwin, A. E., Holahan, M. R., Sadeghian, K., \& Kelley, A. E. (1999). $N$-methyl-D-aspartate receptor-dependent plasticity within a distributed corticostriatal network mediates response-reinforcement learning. Manuscript submitted for publication.

BASSAREO, V. (1997). Differential influence of associative and nonassociative learning mechanisms on the responsiveness of prefrontal and accumbal dopamine transmission to food stimuli in rats fed ad libitum. Journal of Neuroscience, 17, 851-861.

Basso, A. M., \& Kelley, A. E. (1999). Feeding induced by GABAA receptor stimulation within nucleus accumbens shell: Regional mapping and characterization of macronutrient and taste preference. $B e$ havioral Neuroscience, 113, 324-336.

BeCK, C. H., \& Fibiger, H. C. (1995). Conditioned fear-induced changes in behavior and in the expression of the immediate early gene c-fos: With and without diazepam pretreatment. Journal of Neuroscience, 15, 709-720.

BECKSTEAD, R. M. (1979). An autoradiographic examination of corticocortical and subcortical projections of the mediodorsal-projection (prefrontal) cortex in rats. Journal of Comparative Neurology, 84, 43-62.

BENINGER, R. J. (1983). The role of dopamine in locomotor activity and learning. Brain Research Reviews, 6, 173-196.

Beninger, R. J., \& Phillips, A. G. (1980). The effect of pimozide on the establishment of conditioned reinforcement. Psychopharmacology, 68, 147-158.

Berridge, C. W., Stratford, T. L., Foote, S. L., \& Kelley, A. E. (1997). Distribution of dopamine- $\beta$-hydroxylase(DBH)-like immunoreactive fibers within the shell of the nucleus accumbens. Synapse, 27, 230-241

Berridge, K. C., Venier, I. L., \& Robinson, T. E. (1989). Taste reactivity analysis of 6-hydroxydopamine-induced aphagia: Implications for arousal and anhedonia hypotheses of dopamine function. Behavioral Neuroscience, 103, 36-45.

BINDRA, D. (1968). Neuropsychological interpretation of the effects of drive and incentive-motivation on general and instrumental behavior. Psychological Review, 75, 1-22.

BindRA, D. (1978). How adaptive behavior is produced: A perceptualmotivational alternative to response-reinforcement. Behavioral \& Brain Sciences, 1, 41-91.

Boeijinga, P. H., Mulder, A. B., Pennartz, C. M., Manshanden, I., \& LOPES DA SILVA, F. H. (1993). Responses of the nucleus accumbens following fornix/fimbria stimulation in the rat: Identification and long-term potentiation of mono- and polysynaptic pathways. Neuroscience, 53, 1049-1058.

Bolles, R. C. (1975). Learning theory. New York: Holt, Rinehart \& Winston.

Bowman, E. M., Aigner, T. G., \& Richmond, B. J. (1996). Neural signals in the monkey ventral striatum related to motivation for juice and cocaine rewards. Journal of Neurophysiology, 75, 1061-1073.

Brog, J. S., Salyapongse, A., Deutch, A. Y., \& Zahm, D. S. (1993). The patterns of afferent innervation of the core and shell in the "ac- cumbens" part of the rat ventral striatum: Immunohistochemical detection of retrogradely transported fluoro-gold. Journal of Comparative Neurology, 338, 255-278.

Brown, M. A., \& SHARP, P. E. (1995). Simulation of spatial learning in the Morris water maze by a neural network model of the hippocampal formation and nucleus accumbens. Hippocampus, 5, 171-188.

Brown, T. H., Kairiss, E. W., \& Keenan, C. L. (1990). Hebbian synapses: Biophysical mechanisms and algorithms. Annual Review of Neuroscience, 13, 475-511.

CAdor, M., Robbins, T. W., \& Everitt, B. J. (1989). Involvement of the amygdala in stimulus-reward associations: Interaction with the ventral striatum. Neuroscience, 30, 77-87.

Caine, S., Heinrichs, S. C., Coffin, V., \& Koob, G. F. (1995). Effects of the dopamine D-1 antagonist SCH 23390 microinjected into the accumbens, amygdala or striatum on cocaine self-administration. Brain Research, 692, 47-56.

Calabresi, P., Pisani, A., Mercuri, N. B., \& Bernardi, G. (1996) The corticostriatal projection: From synaptic plasticity to dysfunctions of the basal ganglia. Trends in Neuroscience, 19, 19-24.

Carlezon, W. A., Devine, D. P., \& Wise, R. A. (1995). Habit-forming actions of nomifensine in nucleus accumbens. Psychopharmacology, 122, 194-197.

Carlezon, W. A., \& Wise, R. A. (1996). Rewarding actions of phencyclidine and related drugs in nucleus accumbens shell and frontal cortex. Journal of Neuroscience, 16, 3112-3122.

Cepeda, C., Buchwald, N. A., \& Levine, M. S. (1993). Neuromodulatory actions of dopamine in the neostriatum are dependent upon the excitatory amino acid receptor subtypes activated. Proceedings of the National Academy of Sciences, 90, 9576-9580.

DAUNAIS, J. B., \& MCGINTY, J. F. (1994). Acute and chronic cocaine administration differentially alters striatal opioid and nuclear transcription factor mRNAs. Synapse, 18, 35-45.

Daunais, J. B., RoberTs, D. C. S., \& McGinty, J. F. (1995). Short-term cocaine self administration alters striatal gene expression. Brain Research Bulletin, 37, 523-527.

DeUtCh, A. Y., \& CAMERON, D. S. (1992). Pharmacological characterization of dopamine systems in the nucleus accumbens core and shell. Neuroscience, 46, 49-56.

Dickinson, A. (1980). Contemporary animal learning theory. Cambridge: Cambridge University Press.

Divac, I. (1972). Neostriatum and functions of prefrontal cortex. Acta Neurobiologica Experimentalis, 32, 461-477.

EVANS, K. R., \& VACCARINO, F. J. (1986). Intra-nucleus accumbens amphetamine: Dose-dependent effects on food intake. Pharmacology, Biochemistry \& Behavior, 25, 1149-1151.

EVENDEN, J. L., \& CARLI, M. (1985). The effects of 6-hydroxydopamine lesions of the nucleus accumbens and caudate nucleus of rats on feeding in a novel environment. Behavioural Brain Research, 15, 63-70.

EveritT, B. J., CADOR, M., \& RobBins, T. (1989). Interactions between the amygdala and ventral striatum in stimulus-reward associations: Studies using a second-order schedule of sexual reinforcement. Neuroscience, 30, 63-75.

Floresco, S. B., Seamans, J. K., \& Phillips, A. G. (1996). Differential effects of lidocaine infusions into the ventral $\mathrm{CAl} /$ subiculum or the nucleus accumbens on the acquisition and retention of spatial information. Behavioural Brain Research, 81, 163-172.

Floresco, S. B., Seamans, J. K., \& Phillips, A. G. (1997). Selective roles for hippocampal, prefrontal cortical, and ventral striatal circuits in radial-arm maze tasks with or without a delay. Journal of Neuroscience, 17, 1880-1890.

FonNUM, F. (1984). Glutamate: A neurotransmitter in mammalian brain Journal of Neurochemistry, 42, 1-10.

Graybiel, A. M., Moratalla, R., \& Robertson, H. A. (1990). Amphetamine and cocaine induce drug-specific activation of the $c$-fos gene in striosome-matrix compartments and limbic subdivisions of the striatum. Proceedings of the National Academy of Sciences, $\mathbf{8 7}$, 6912-6916

Groenewegen, H. J., \& Russchen, F. T. (1984). Organization of the ef ferent projections of the nucleus accumbens to pallidal, hypothalamic, 
and mesencephalic structures: A tracing and immunohistochemical study in the cat. Journal of Comparative Neurology, 223, 347-367.

Groenewegen, H. J., Wright, C. I., \& Beijer, A. V. J. (1996). The nucleus accumbens: Gateway for limbic structures to reach the motor system? Progress in Brain Research, 107, 485-511.

HebB, D. O. (1949). The organization of behavior. New York: Wiley.

Heimer, L., Alheid, G. F., \& ZAHM, D. S. (1993). Basal forebrain organization: An anatomical framework for motor aspects of drive and motivation. In P. W. Kalivas \& C. D. Barnes (Eds.), Limbic motor circuits and neuropsychiatry (pp. 1-44). Boca Raton, FL: CRC Press.

Heimer, L., Zahm, D. S., Churchill, L., Kalivas, P. W., \& WohltMANN. C. (1991). Specificity in the projection patterns of accumbal core and shell in the rat. Neuroscience, 41, 89-125.

Hernandez, L., \& Hoebel, B. G. (1988). Feeding and hypothalamic stimulation increase dopamine turnover in the accumbens. Physiology \& Behavior, 44, 599-606.

Holahan, M. R., Kalin, N. H., \& Kelley, A. E. (1997). Microinfusion of corticotropin-releasing factor into the nucleus accumbens shell results in increased behavioral arousal and oral motor activity. Psychopharmacology, 130, 189-196.

Hope, B., Kosofsky, B., Hyman, S. E., \& Nestler, E. J. (1992). Regulation of immediate early gene expression and AP-1 binding in the rat nucleus accumbens by chronic cocaine. Proceedings of the $\mathrm{Na}$ tional Academy of Sciences, 89, 5764-5768.

Horger, B. A., ElsworTh, J. D., \& RoTH, R. H. (1995). Selective increase in dopamine utilization in the shell subdivision of the nucleus accumbens by the benzodiazepine inverse agonist FG 7142. Journal of Neurochemistry, 65, 770-774.

Houk, J. C., ADAMs, J. L., \& Barto, A. G. (1995). A model of how the basal ganglia generate and use neural signals that predict reinforcement. In J. C. Houk, J. L. Davis, \& D. G. Beiser (Eds.), Models of information processing in the basal ganglia (pp. 249-270). Cambridge, MA: MIT Press.

Houk, J. C., \& WISE, S. P. (1995). Distributed modular architectures linking basal ganglia, cerebellum and cerebral cortex: Their role in planning and controlling action. Cerebral Cortex, 5, 95-110.

Hull, C. L. (1943). Principles of behavior. New York: Appleton.

JAmes, W. (1890). Psychology: Briefer course. Cambridge, MA: Harvard University Press.

JOEL, D., \& WEINER, I. (1994). The organization of the basal gangliathalamocortical circuits: Open interconnected rather than closed segregated. Neuroscience, 63, 363-379.

Kalivas, P. W., \& DufFy, P. (1995). Selective activation of dopamine transmission in the shell of the nucleus accumbens by stress. Brain Research, 675, 325-328.

KeLLEY, A. E., \& DOMESICK, V. B. (1982). The distribution of the projection from the hippocampal formation to the nucleus accumbens in the rat: An anterograde- and retrograde-horseradish peroxidase study. Neuroscience, 7, 2321-2335.

Kelley, A. E., Domesick, V. B., \& Nauta, W. J. H. (1982). The amygdalostriatal projection in the rat: An anatomical study by anterograde and retrograde tracing methods. Neuroscience, 7, 615-630.

Kelley, A. E., Holahan, M. R., Smith-Roe, S., \& Baldwin, A. E. (1997). NMDA receptors and intracellular mechanisms within nucleus accumbens core are involved in appetitive learning. Society for Neuroscience Abstracts, 23, 2119.

Kelley, A. E., Smith-Roe, S., \& Holahan, M. R. (1997). Responsereinforcement learning is dependent on NMDA receptor activation in the nucleus accumbens core. Proceedings of the National Academy of Sciences, 94, 12174-12179.

Kelley, A. E., \& Swanson, C. J. (1998). Feeding induced by blockade of AMPA and kainate receptors within the ventral striatum: A microinfusion mapping study. Behavioural Brain Research, 89, 107-113.

KING, D., \& FinLAY, J. M. (1997). Loss of dopamine terminals in the medial prefrontal cortex increased the ratio of DOPAC to DA in tissue of the nucleus accumbens shell: Role of stress. Brain Research, 767, $192-200$

KiYatKIn, E. A., \& Gratton, A. (1994). Electrochemical monitoring of extracellular dopamine in nucleus accumbens of rats lever-pressing for food. Brain Research, 652, 225-234.
KLUVer, H. M., \& BuCY, P. C. (1939). Preliminary analysis of functions of the temporal lobes in monkeys. Archives of Neurology \& Psychiatry, 42, 979-1000.

Kombian, S. B., \& MalenKa, R. C. (1994). Simultaneous LTP of nonNMDA and LTD of NMDA-receptor mediated responses in the nucleus accumbens. Nature, 368, 242-245.

Konradi, C., Leveque, J. C., \& Hyman, S. E. (1996). Amphetamine and dopamine-induced immediate early gene expression in striatal neurons depends on postsynaptic NMDA receptors and calcium. Journal of Neuroscience, 16, 4231-4239.

KoRNhUBER, H. H. (1974). Cerebral cortex, cerebellum, and basal ganglia: An introduction to their motor functions. In F. O. Schmitt \& F. G. Worden (Eds.), The neurosciences: Third study program (pp. 267280). Cambridge: MIT Press.

KörTER, R. (1994). Postsynaptic integration of glutamatergic and dopaminergic signals in the striatum. [Review]. Progress in Neurobiology, 44, 163-196.

LASHLEY, K. S. (1938). An experimental analysis of instinctive behavior. Psychological Review, 45, 445-471.

Lovinger, D. M., Tyler, E. C., \& Merritt, A. (1993). Short- and longterm synaptic depression in rat neostriatum. Journal of Neurophysiology, 70, 1937-1949.

MacLean, P. (1949). Psychosomatic disease and the "visceral brain." Psychosomatic Medicine, 11, 338-353.

Maldonado-IRIZARRY, C. S., \& Kelley, A. E. (1994). Differential behavioral effects following microinjection of an NMDA antagonist into nucleus accumbens subregions. Psychopharmacology, 166, 65-72.

Maldonado-IrizarRy, C. S., \& Kelley, A. E. (1995). Excitatory amino acid receptors within nucleus accumbens subregions differentially mediate spatial learning in the rat. Behavional Pharmacology, 6, 527-539.

Maldonado-IrizarRy, C. S., Swanson, C. J., \& Kelley, A. E. (1995). Glutamate receptors in the nucleus accumbens shell control feeding behavior via the lateral hypothalamus. Journal of Neumscience, 15, 6779-6788.

McDonald, A. J. (1991). Topographical organization of amygdaloid projections to the caudatoputamen, nucleus accumbens, and related striatal-like areas of the rat brain. Neurascience, 44, 15-33.

McDonald, R. J., \& White, N. M. (1993). A triple dissociation of memory systems: Hippocampus, amygdala, and dorsal striatum. Behavioral Neuroscience, 107, 3-22.

McGeer, P. L., McGeer, E. G., Scherer, U., \& Singh, K. (1977). A glutamatergic corticostriatal pathway? Brain Research, 128, 369-373.

Mishkin, M., \& Petri, H. L. (1984). Memories and habits: Some implications for the analysis of learning and retention. In N. Butters \& L. R. Squire (Eds.), Neuropsychology of memory (pp. 287-296). New York: Guilford.

Mogenson, G. J., Jones, D. L., \& Yim, C. Y. (1980). From motivation to action: Functional interface between the limbic system and the motor system. Progress in Neurobiology, 14, 69-97.

Mogenson, G. J., \& NIELSEN, M. (1984). Neuropharmacological evidence to suggest that the nucleus accumbens and subpallidal region contribute to exploratory locomotion. Behavioral \& Neural Biology, 42, 52-60.

Mogenson, G. J., Swanson, L. W., \& Wu, M. (1983). Neural projections from nucleus accumbens to globus pallidus, substantia innominata, and lateral preoptic-lateral hypothalamic area: An anatomical and electrophysiological investigation in the rat. Journal of Neuroscience, 3, 189-202.

Mountcastle, V. B., Lynch, J. C., Georgopoulos, A., Sakata, H., \& ACuNA, C. (1975). Posterior parietal association cortex of the monkey: Command functions for operations within extrapersonal space. Journal of Neurophysiology, 38, 871-908.

Mulder, A. B., ARTS, M. P., \& Lopes da Silva, F. H. (1997). Short- and long-term plasticity of the hippocampus to nucleus accumbens and prefrontal cortex pathways in the rat, in vivo. European Journal of Neuroscience, 9, 1603-1611.

Nauta, W. J. H. (1971). The problem of the frontal lobe: A reinterpretation. Joumal of Psychiatric Research, 8, 167-187.

Nauta, W. J. H., Smith, G. P., Faull, R. L. M., \& Domestck, V. B. (1978). Efferent connections and nigral afferents of the nucleus accumbens septi in the rat. Neuroscience, 3, 385-401. 
O'Donnel., P. (1999). Ensemble coding in the nucleus accumbens. Psychobiology, 27, 187-197.

PaCkard, M. G., \& McGaugh, J. L. (1992). Double dissociation of fornix and caudate nucleus lesions on acquisition of two water maze tasks: Further evidence for multiple memory systems. Behavioral Neuroscience, 106, 439-446.

Parkinson, J. A., Olmstead, M. C., Burns, L. H., RobBins, T. W., \& EveritT, B. J. (1999). Dissociation in effects of lesions of the nucleus accumbens core and shell in appetitive Pavlovian approach behavior and the potentiation of conditioned reinforcement and locomotor activity by d-amphetamine. Journal of Neuroscience, 19, 2401-2411

Pennartz, C. M., Ameerun, R. F., Groenewegen, H. J., \& Lopes DA SILVA, F. H. (1993). Synaptic plasticity in an in vitro slice preparation of the rat nucleus accumbens. European Journal of Neuroscience, 5, 107-117.

Pennartz, C. M., Groenewegen, H. J., \& Lopes da Silva, F. H. (1994). The nucleus accumbens as a complex of functionally distinct neuronal ensembles: An integration of behavioural, electrophysiological and anatomical data. Progress in Neurobiology, 42, 719-761.

Pich, E. M., Pagliusi, S. R., Tessari, M., Talabot-Ayer, D., Hooft van Huijsduijnen, R., \& Chiamulera, C. (1997). Common neural substrates for the addictive properties of nicotine and cocaine. Science, $275,83-86$

Pontieri, F. E., Tanda, G., \& Di Chiara, G. (1995). Intravenous cocaine, morphine, and amphetamine preferentially increase extracellular dopamine in the "shell" as compared with the "core" of the rat nucleus accumbens. Proceedings of the National Academy of Sciences, 92, 12304-12308.

Pontieri, F. E., Tanda, G., Orzi, F., \& Di Chiara, G. (1996). Effects of nicotine on the nucleus accumbens and similarity to those of addictive drugs. Nature, 382, 255-257.

PRIBAm, K. H. (1969). The primate prefrontal cortex. Neuropsychologia, 7, 259-266.

Reading, P. J., Dunnett, S. B., \& Robbins, T. W. (1991). Dissociable roles of the ventral, medial and lateral striatum on the acquisition and performance of a complex visual stimulus-response habit. Behavioural Brain Research, 45, 147-161.

Redish, A. D., \& Touretsky, D. S. (1997). Cognitive maps beyond the hippocampus. Hippocampus, 7, 15-35.

RobBins, T. W. (1978). The acquisition of responding with conditioned reinforcement: Effects of pipradrol, methylphenidate, $d$-amphetamine, and nomifensine. Psychopharmacology, 58, 79-87.

RobBins, T. W., \& EveritT, B. J. (1996). Neurobehavioural mechanisms of reward and motivation. Current Opinion in Neurobiology, 6, 228-236.

Robinson, T. E., \& Berridge, K. C. (1993). The neural basis of drug craving: An incentive-sensitization theory of addiction. Brain Research Reviews, 18, 247-291.

Schultz, W., Apicella, P., \& Ljungberg, T. (1993). Responses of monkey dopamine neurons to reward and conditioned stimuli during successive steps of learning a delayed response task. Journal of Neuroscience, 13, 900-913.

Schultz, W., Dayan, P., \& Montague, P. R. (1997). A neural substrate of prediction and reward. Science, 275, 1593-1598.

SETLOW, B. (1997). The nucleus accumbens and learning and memory. Journal of Neuroscience Research, 49, 515-521.

SimpSon, J. N., WANG, J. Q., \& McGinTY, J. F. (1995). Repeated amphetamine administration induces a prolonged augmentation of phosphorylated cyclase response element-binding protein and Fos-related antigen immunoreactivity in rat striatum. Neuroscience, 69, 441-457.

SMITH, A. D., \& Bolam, J. P. (1990). The neural network of the basal ganglia as revealed by the study of synaptic connections of identified neurones. Trends in Neurosciences, 13, 259-265.

Smith-Roe, S., Sadeghian, K., \& Kelley, A. E. (in press). Spatial learning and performance in the radial arm maze is impaired following NMDA receptor blockade in striatal subregions. Behavioral Neuroscience.

Solomon, R. L., \& CoRBIT, J. P. (1974). An opponent-process theory of motivation: I. Temporal dynamics of affect. Psychological Review, 81, 119-145.

SPENCE, K. W. (1947). The role of secondary reinforcement on delayed reward learning. Psychological Review, 54, 1-8.

SPENCER, H. (1872). The principles of psychology. New York: AppletonCentury-Crofts.

Stanley, B. G., Willet III, V. L., Donias, H. W., Ha, L. H., \& Spears, L. C. (1993). The lateral hypothalamus: Primary site mediating excitatory amino acid-elicited feeding. Brain Research, 630, 41-49.

Stellar, E. (1954). The physiology of motivation. Psychological Review, 61, 5-21.

Stellar, E. (1960). Drive and Motivation. In H. W. Magoun (Ed.), Handbook of Physiology: Section I. Neurophysiology (Vol. III, pp. 15011527). Washington, DC: American Physiological Society

StratFord, T. R., \& Kelley, A. E. (1997a). Feeding elicited by inhibition of neurons in the nucleus accumbens shell depends on activation of neurons in the lateral hypothalamus. Society for Neuroscience Abstracts, 23, 577.

STRATFORD, T. R., \& KELLEY, A. E. (1997b). GABA in the nucleus accumbens shell participates in the central regulation of feeding behavior. Journal of Neuroscience, 17, 4434-4440.

Stratford, T. R., Swanson, C. J., \& Kelley, A. E. (1998). Specific changes in food intake elicited by blockade or activation of glutamate receptors in the nucleus accumbens shell. Behavioural Brain Research, 93, 43-50.

Sutherland, R. J., \& Rodriguez, A. J. (1989). The role of the fornix/fimbria and some related subcortical structures in place learning and memory. Behavioural Brain Research, 32, 265-277.

Swanson, C. J., Heath, S., Stratford, T. R., \& Kelley, A. E. (1997). Differential behavioral responses to dopaminergic stimulation of nucleus accumbens subregions in the rat. Pharmacology, Biochemistry \& Behavior, 58, 933-945.

TAYLOR, J. R., \& RoBBINS, T. W. (1984). Enhanced behavioural control by conditioned reinforcers following microinjections of d-amphetamine into the nucleus accumbens. Psychopharmacology, 84, 405-412.

TAYLOR, J. R., \& ROBBins, T. W. (1986). 6-Hydroxydopamine lesions of the nucleus accumbens, but not of the caudate nucleus, attenuate enhanced responding with reward-related stimuli produced by intraaccumbens d-amphetamine. Psychopharmacology, 90, 390-397.

THORNDIKE, E. (1911). Animal intelligence. New York: Macmillan.

TIDEY, J. W., \& MiCZEK, K. A. (1996). Social defeat stress selectively alters mesocorticolimbic dopamine release: An in vivo microdialysis study. Brain Research, 721, 140-149.

UChimura, N., \& NorTh, R. A. (1991). Baclofen and adenosine inhibit synaptic potentials mediated by gamma-aminobutyric acid and glutamate release in rat nucleus accumbens. Journal of Pharmacology \& Experimental Therapeutics, 258, 663-668.

UNO, M., \& OzAWA, N. (1991). Long-term potentiation of the amygdalastriatal synaptic transmission in the course of development of amygdaloid kindling in cats. Neuroscience Research, 12, 251-262.

VALENSTEIN, E. S. (1969). Behavior elicited by hypothalamic stimulation: A prepotency hypothesis. Brain Behavior \& Evolution, 2, 295-316.

van den Bos, R., Charria Ortiz, G. A., \& Cools, A. R. (1992). Injections of the NMDA-antagonist D-2-amino-7-phosphonoheptanoic acid (AP-7) into the nucleus accumbens of rats enhance switching between cue-directed behaviours in a swimming test procedure. $\mathrm{Be}$ havioural Brain Research, 48, 165-170.

VoORn, P., Jorritsma-Byham, B., VAN Dijk, C., \& Buiss, R. M. (1986). The dopaminergic innervation of the ventral striatum in the rat: A lightand electron-microscopical study with antibodies against dopamine. Journal of Comparative Neurology, 251, 84-99.

WANG, J. Q., Daunais, J. B., \& McGinTY, J. F. (1994). NMDA receptors mediate amphetamine-induced upregulation of zif $/ 268$ and preprodynorphin mRNA expression in rat striatum. Synapse, 18, 343-353.

WANG, J. Q., \& MCGINTY, J. F. (1995). Alterations in striatal zif/268, preprodynorphin and preproenkephalin mRNA expression induced by repeated amphetamine administration in rats. Brain Research, 673 262-274.

WANG, J. Q., Smith, A. J., \& McGinty, J. F. (1995). A single injection 
of amphetamine or methamphetamine induces dynamic alterations in c-fos, zif/268 and preprodynorphin messenger RNA expression in rat forebrain. Neuroscience, 68, 83-95.

WEINER, I. (1990). Neural substrates of latent inhibition: The switching model. Psychological Bulletin, 108, 442-461.

Wickens, J. R., BeGG, A. J., \& ARBUthnotT, G. W. (1996). Dopamine reverses the depression of rat corticostriatal synapses which normally follows high-frequency stimulation of cortex in vitro. Neuroscience, 70, 1-5.

WiCKENS, J. [R.], \& KötTER, R. (1995). Cellular models of reinforcement. In J. C. Houk, J. L. Davis, \& D. G. Beiser (Eds.), Information processing in the basal ganglia (pp. 187-214). Cambridge, MA: MIT Press.

Wilson, C., Nomikos, G. G., Collu, M., \& Fibiger, H. C. (1995). Dopaminergic correlates of motivated behavior: Importance of drive. Journal of Neuroscience, 15, 5169-5178.

WISE, R. A., \& RoMPRE, P. P. (1989). Brain dopamine and reward. Annual Review of Psychology, 40, 191-225.

Wise, S. P., MurRay, E. A., \& GerFen, C. R. (1996). The frontal cortexbasal ganglia system in primates. Critical Reviews in Neurobiology, 10, 317-356.

Wolf, M. E., White, F. J., \& Hu, X.-T. (1994). MK-801 prevents alterations in the mesoaccumbens dopamine system associated with behavioral sensitization to amphetamine. Journal of Neuroscience, 14, 1735-1745.
Wright, C. I., BeiJer, A. V., \& Groenewegen, H. J. (1996). Basal amygdaloid complex afferents to the rat nucleus accumbens are compartmentally organized. Journal of Neuroscience, 16, 1877-1893.

Wright, C. I., \& Groenewegen, H. J. (1996). Pattern of overlap and segregation between insular cortical, intermediodorsal thalamic and basal amygdaloid afferents in the nucleus accumbens. Neuroscience, 73, 359-373.

ZAHM, D. S., \& BROG, J. S. (1992). On the significance of subterritories in the "accumbens" part of the rat ventral striatum. Neuroscience, $\mathbf{5 0}$, 751-767.

Zhang, M., Gosnell, B. A., \& Kelley, A. E. (1998). Intake of highfat food is selectively enhanced by mu opioid receptor stimulation within the nucleus accumbens. Joumal of Pharmacology \& Experimental Therapeutics, 284, 908-914.

ZhaNG, M., \& KelleY, A. E. (1997). Opiate agonists microinejected into the nucleus accumbens enhance sucrose drinking in rats. Psychopharmacology, 132, 350-360.

Zhang, M., \& Kelley, A. E. (1998). Striatal modulation of opioidinduced palatable feeding: Anatomical mapping studies. Society for Neuroscience Abstracts, 24, 706.

(Manuscript received September 29, 1998; revision accepted for publication February 19, 1999.) 